\title{
THE EFFECTS OF GREEN MARKETING PRACTICES ON GREEN EQUITY AND CUSTOMER TOLERANCE
}

\author{
DOI: 10.17261/Pressacademia.2020.1283 \\ JMML- V.7-ISS.3-2020(1)-p.102-111
}

\section{Edin Guclu Sozer}

Istanbul Okan University, Faculty of Business and Administrative Sciences, Business Administration Department, Tuzla, Istanbul, Turkey. edin.sozer@okan.edu.tr, ORCID: 0000-0003-4984-4629

Date Received: June 17, 2020

Date Accepted: September 6, 2020

To cite this document

Sozer, E. G. (2020). The effects of green marketing practices on green equity and customer tolerance. Journal of Management, Marketing and Logistics (JMML), V.7(3), p.102-111

Permanent link to this document: http://doi.org/10.17261/Pressacademia.2020.1283

Copyright: Published by PressAcademia and limited licensed re-use rights only.

\begin{abstract}
Purpose- This study targets to fill an important gap in the green marketing literature by integrating two inter-related concepts, Green Brand Equity and Customer Based Brand Tolerance (CBBT).

Methodology- The participants of the study were female consumers aged between 18-35, users of personal care and cosmetic products and residents of Istanbul city. The product category selected for the purpose of this study was personal care and cosmetics. The research model and the respective hypothesis proposed to identify the determinants of Green Brand Equity and its effect on CBBT were tested by utilizing the Structural Equation Modeling (SEM).

Findings- The results of the study confirm that green brand satisfaction and green brand trust are the two determinants of Green Brand Equity. In turn, the results also indicate that a strong Green Brand Equity generates a positive effect on Customer Based Brand Tolerance by increasing consumers' Performance Tolerance, Price Tolerance as well as Communication Tolerance levels towards the brand.

Conclusion- Overall, the study reports a positive impact of Green Brand Equity on Customer Based Brand Tolerance (CBBT). Academic as well as managerial implications are provided based on these findings
\end{abstract}

Keywords: Green marketing, green brand equity, brand equity, customer based brand tolerance. JEL Codes: M30, M31, M39

\section{INTRODUCTION}

Unprecedented population growth in the last couple of decades followed by rising global economic activities and consumption levels, led to the uncontrolled utilization of natural resources which eventually caused severe environmental problems including natural resource shortages for the next generations, pollution, and natural disasters. These problems reached at critical levels which started to be threaten the life of future generations. As a response to these problems, starting from mid-seventies, environmental movements are organized by sensitive consumer groups to attract the attention of the society on environmental issues. One of the historical developments was the introduction of "Sustainable Development" concept in 1987 by the World Commission on Environment and Development in their report titled "Our Common Future". This development accelerated the adoption of sustainability approach socially, politically as well as economically in the societies which in turn caused the individuals and businesses to focus more on the environmental problems and increased their sensitivity. Thus, in addition to global and macro-economic context, sustainability emerged as a critical issue in the business processes and the lifestyles of individuals (Cantele \& Cassia, 2020). In line with their responsibility towards the society, businesses started to adopt strategies and processes which are expected to generate sustainable business models (Baumgartner \& Rauter, 2017; Ottman, 1992). On the other hand, sensitive consumers to environmental problems started to be selective on their product selections in favor of environmentally friendly companies (Chen, 2010).

This new trend of environmental protectionism led to the rise of a new marketing practice called as Green Marketing. Since its introduction for the first time in American Marketing Associations conference in 1975, green marketing became one of the most critical and sensitive component of the marketing strategies and programs for many companies. In its basic form green marketing 
can be defined as the marketing programs intended to satisfy the needs of target consumers through practices which are sensitive to environmental issues (Aytekin, 2007). Most academicians as well as professionals agree that green marketing practices should not be limited to only product concept but needs also to be implemented on a larger scale covering all other activities of the companies with the ultimate target of building a competent green brand which greens all other components of the marketing mix (Kang \& Hur, 2012; Chen, 2010). Thus, building a strong green brand, consequently generating a strong green equity, requires large investments. In order to compensate these large investments with financial and performance returns, the identification of the determinants of green brand equity and exploring how green brand equity influences consumer behavior are essential to understand. One of the important dimensions of consumer behavior is the tolerance of consumers towards the brands. Marketing literature includes several studies which focused on the determinants of green equity construct, where three components, namely green image, green satisfaction, and green trust, are confirmed as the drivers of the green equity (Ha, 2020; Chen, 2010). On other hand, as reported by Kumar (2015), there are many studies focused on the consequences of green marketing practices in terms of consumer behavior as well as market performance. These studies provide robust frameworks and strong base of knowledge in terms of the determinants and outcomes of green marketing practices.

This study targets to fill an important gap in the green marketing literature by measuring the influence of green brand equity on the tolerance level of customers towards that brand in terms of product performance, price, and marketing messages. This tolerance level is measured through the employment of Customer Based Brand Tolerance (CBBT) construct and its associated scale developed by Sözer (2019). In the following section, green brand equity and CBBT constructs are explained in detail, their relationship is elaborated, and research hypothesis as well as research model are proposed. In the third section, the research methodology is presented by explaining the design of the study, sampling methodology employed, and operationalization of the variables. In the fourth and fifth sections, the findings of the study are presented, and academic as well as managerial implications are provided. In the final section, limitations are explained and suggestions for future research studies are provided.

\section{LITERATURE REVIEW}

Several push and pull factors need to be considered to understand the motives which encourage companies to develop green marketing programs. On one hand, companies involve in green marketing programs due to the push factors which include compliance with societal pressures, ethical responsibilities, and legal obligations (Polonsky, 1994). On the other hand, there are also pull factors such as enhancing corporate image, obtaining competitive advantage, and increasing market performance (Chen, 2010). Whatever is the encouraging factor, the ultimate target of companies in going green is to generate a strong green equity and support it. Thus, companies seek for strong green equities by the means of enhancing the environmental performance of their offerings to the market.

\subsection{Green Brand Equity and Its Determinants}

The construct of Green Brand Equity (GBE) can be considered as a derivative of brand equity concept in the environmental context. Although there are various definitions of brand equity provided in the marketing literature, as Aaker (1991) defined, it can be regarded as "a set of brand assets and liabilities linked to a brand, its name and symbol, that add to or subtract from the value provided by a product or service to a firm and/or to that firm's customers". In the branding literature, the concept of brand equity is conceptualized and transformed into a multi-dimensional construct called as Customer Based Brand Equity (CBBE). Kotler and Keller (2016) defined CBBE as "the differential effect of brand knowledge on consumer reactions towards the marketing stimuli and activities of the brand". As proposed by Keller (1993), CBBE construct is composed of four dimensions, namely brand awareness, brand associations, perceived quality, and brand loyalty, which collectively help to the generation of consumer perceptions about the overall superiority of the brand. Based on the grounds provided by the brand equity concept as well as CBBE construct, Chen (2010) proposed the concept of Green Brand Equity (GBE) and defined it as "a set of brand assets and liabilities about green commitments and environmental concerns linked to a brand, its name and symbol that add to or subtract from the value provided by a product or service". Originally proposed by Chen (2010), several other studies in the green marketing literature also identified green brand image, green satisfaction, and green trust as the determinants of GBE (Ha, 2020; Ng et al. 2014; Kang and Hur, 2012).

According to Solomon (2018), a piece of information received by the consumer is stored in the associative network of information and all consumers have such organized systems of concepts related to the brands or companies. Information nodes, namely pieces of information such as concepts, features, and similar information, are the basis of the associative networks. The associations are formed when these nodes are inter-connected in the brain. When some nodes of information are connected to the brand nodes in the memory, they constitute the brand associations and represent the meaning of the brand for consumers (Aaker, 1991). The 
perception of consumers about the brand which is generated through these brand associations represents the image of the brand (Cretu and Brodie, 2007). Thus, brand image can be considered as the collective and combined influence derived through these associations (Biel, 1992). Those brands with strong, favorable, and unique associations in consumer's mind, are expected to have a strong and positive image (Keller, 1993). Based on the previous conceptualizations of brand image, Chen (2010) proposed the green image concept and defined it as "a set of perceptions of a brand in a consumers' mind that is linked to environmental commitments and environmental concerns". There are several studies in the marketing literature which argue and confirm the positive influence of brand image on CBBE (Davis et al. 2008; Faircloth et al. 2001) and the positive influence of green image on GBE (Butt et al. 2016; Namkung and Jang, 2013). In the light of the theoretical framework as well as the findings in the literature, the following hypothesis is proposed:

$\mathrm{H}_{1}$ : Green Brand Image will have a positive effect on Green Brand Equity.

As one of the concepts which has been highly investigated in the marketing literature, customer satisfaction can be defined as an evaluation of consumers towards the brand as a result of multiple interactions (Agustin \& Singh, 2005) or as a result of the last transaction (Oliver, 1993). Thus, the satisfaction level of consumers is set through the comparison of pre-purchase expectations about a brand or product with the post-purchase evaluation of the actual performance. Before setting their satisfaction level, consumers evaluate the brand and company based on the multiple-criteria including product performance, service quality, and overall business performance (Ostrom and lacobucci, 1995). Parallel to the conceptualization of customer satisfaction, Chen (2010) introduced the green satisfaction concept and as "a pleasurable level of consumption-related fulfillment to satisfy a customer's environmental desires, sustainable expectations, and green needs". Thus, green satisfaction is the reflection of consumer post-purchase pleasure arising from the fulfillment of environmental needs and expectations (Chang and Fong, 2010). There are several studies in the marketing literature which argue and confirm the positive effect of customer satisfaction on brand equity (Bekk et al., 2016; Kim et al. 2008) as well as the positive influence of green satisfaction on GBE (Ha, 2020; Chen, 2010). In the light of the theoretical framework as well as the findings in the literature, the following hypothesis is proposed:

$\mathrm{H}_{2}$ : Green Brand Satisfaction will have a positive effect on Green Brand Equity.

Marketing literature credits the concept of trust as one of the main factors in building the relationship between consumers and brands. As Levy (1985) points out, consumers have the tendency to assign human characteristics and personality traits to brands as if they were real people. When such personalization occurs, consumers start to generate their own perception about the brand in a dyadic relationship format based on the trust (Elliot \& Yannopoulou, 2007). Trust, in its basic form, is the belief about reliability and honesty of one side towards the other side and it eliminates the concerns about possible opportunistic behaviors in a relationship (Gulati, 1995). In the context of relationship marketing, trust is expected to be generated through the multiple interactions between the consumers and brands which are consistent, competent, and responsible (Doney and Cannon, 1997). In line with the social exchange theory, when consumers trust a brand, they are expected to commit to their relationship and purchase the products of the brand (Gefen and Straub, 2004; Singh and Sirdeshmukh, 2000). Marketing literature includes several studies focused on the relationship between trust and CBBE and these studies confirmed the positive influence of trust on CBBE (Kim et al. 2008; Jevons and Gabbott, 2000). In his study, Chen (2010) introduced the concept of green trust and defined it as "a willingness to depend on a product, service, or brand based on the belief or expectation resulting from its credibility, benevolence, and ability about its environmental performance". In line with the studies which measured the influence of brand trust on CBBE and confirmed its positive effects, green trust was also found affective on GBE (Ha, 2020; Chen, 2010). In the light of the theoretical framework as well as the findings in the literature, the following hypothesis is proposed:

$\mathrm{H}_{3}$ : Green Brand Trust will have a positive effect on Green Brand Equity.

\subsection{The Influence of Green Brand Equity on Customer Based Brand Tolerance (CBBT)}

Tolerance is one of the concepts which is widely used in many scientific fields including the social sciences. Basically, tolerance can be defined as a state of internal paradox resulting from accepting to do something which is not ideally preferred (Doorn, 2012). In the context of relationship marketing, tolerance can be defined as the acceptance of undesirable or unexpected costs incurred as a result of the interactions between the customer and brand during the relationship journey. Careful review of studies in the marketing literature shows that most of the studies are mainly focused on the tolerance related to the financial costs such as the price level and consequently there is a lack of studies which focus on the other types of costs, such as performance, time or even psychological costs, which may incur during the relationship. In line with the tolerance concept and in order to fill the gap in marketing literature, Sözer (2019) introduced the Customer Based Brand Tolerance (CBBT), which is a multi-dimensional construct composed of three dimensions including performance, price, and communication tolerance. 
It is strongly argued and confirmed in the marketing literature that strong CBBE is the pre-requisite for superior market performance as well as strong customer equity (Leone et al. 2006). The strength of the CBBE is found to be directly affective on market performance (Kim and Kim, 2005), purchase intentions (Jalilvand et al. 2011), and customer loyalty (Taylor et al. 2004) collectively generating a more committed customer base, which in turn is expected to be more tolerant towards the brand in cases of unexpected or undesired costs occurred during the journey of the customer with the brand (Sözer, 2019). As confirmed by other studies in the marketing literature, customers of those brands with strong CBBE are expected to accept higher prices for the products of those brands (Kabadayı and Aygün, 2007), be more tolerant towards the product failures and provide a chance for recovery (Sözer, 2019) and finally, be more responsive, selectively attentive and tolerant towards the communication efforts of those brands (Kent and Allen, 1994). Thus, in line with the previous arguments and findings in the literature, it is strongly believed that a strong GBE will also have a positive effect on the generation of committed customer base, and this will lead to increasing performance, price and communication tolerance towards the brand. In the light of the theoretical framework as well as the findings in the literature, the following hypotheses are proposed:

$\mathrm{H}_{4}$ : Green Brand Equity (GBE) will have a positive effect on performance dimension of CBBT.

$\mathrm{H}_{5}$ : Green Brand Equity (GBE) will have a positive effect on price dimension of CBBT.

$\mathrm{H}_{6}$ : Green Brand Equity (GBE) will have a positive effect on communication dimension of CBBT.

The conceptual model of the study and the associated hypotheses which are proposed based on the existing literature are presented in Figure 1.

Figure 1: Conceptual Model and Hypotheses Proposed



\section{DATA AND METHODOLOGY}

\subsection{Research Design}

The objective of this study was to integrate two inter-related constructs, namely Green Brand Equity (GBE) and Customer Based Brand Tolerance (CBBT), and consequently filling the gap in the literature. The product category selected for the purpose of this study was personal care and cosmetics and the participants of the study were the female consumers due to the fact that they were more heavy users of such products compared to male consumers. The participants of the study were female consumers aged between 18-35, users of personal care and cosmetic products and residents of Istanbul city. The total number of participants who were asked to fill-out the questionnaires were 450 , however a total of 412 complete online questionnaires were returned.

Respondents were distributed the questionnaires composed of the statements which were intended to measure the variables in the conceptual model of the study. Due to the fact that the participants of the study were limited to a group of consumers with a specific gender and ager interval, there were no demographic questions employed in the questionnaire. In the beginning of the questionnaire participants were provided some explanation and examples about green marketing practices to generate a basic understanding of environmentally friendly applications in the product category. Following this explanation, participants were asked to think about the brand or store chain which was their favorite in the purchases for personal care and cosmetics products, and then they were asked to fill out the questionnaire based on their favorite brand or store chain. 
Following the data entry and non-response error checking, 412 valid questionnaires were employed for the analysis of the results. Following the confirmation related to the validity and reliability of the scales employed, hypotheses were tested by employing the Structural Equation Modeling (SEM). All statistical analyses in the study were made using IBM SPSS and IBM SPSS AMOS software, version 26.

\subsection{Operationalization of Variables}

The variables in the research model are measured through the scales which are borrowed from the previous studies in the marketing literature. All scales were translated to Turkish language for the purpose of this study. The scale group which represents Green Brand Equity (GBE) and its determinants, namely Green Brand Image, Green Brand Satisfaction and Green Brand Trust, were borrowed from the study of $\mathrm{Ha}$ (2020). The five points Likert-type scales with 1 to 5 ranging from "strongly disagree" to "strongly agree" were originally developed and validated by Chen (2010). Green Brand Image is composed of six items, it was validated by the respective authors and the internal reliability (Cronbach Alpha) score for the scale was reported as .918 and .744, respectively. Green Brand Satisfaction is composed of four items, it was validated by the respective authors and the internal reliability (Cronbach Alpha) score for the scale was reported as .896 and .724, respectively. Green Brand Trust is composed of three items, it was validated by the respective authors and the internal reliability score (Cronbach Alpha) for the scale was reported as .932 and .768, respectively. Finally, Green Brand Equity (GBE) scale is composed of four items, it was validated by the respective authors and the internal reliability score (Cronbach Alpha) for the scale was reported as .837 and .876 , respectively. On the other hand, Customer Based Brand Tolerance (CBBT) construct is composed of Performance Toleration, Price Toleration, and Communication Toleration scales. Five points, three items, Likert-type scales with 1 to 5 ranging from "strongly disagree" to "strongly agree" were originally developed and validated by Sözer (2019). The author reported satisfactory internal reliability (Cronbach Alpha) scores of .926, .743, and .884, for Performance Toleration, Price Toleration, and Communication Toleration scales, respectively.

In order to confirm the validity and reliability of the scales employed, A Confirmatory Factor Analysis (CFA) was conducted. All factor items which constitute the six variables employed in the research model were included into the analysis. The results of CFA confirmed the construct validity by resulting in satisfactory levels of fit indices ( $X 2 / D F=1.070, C F I=0.934, I F I=0.943, R M S E A=0.022$ ) as confirmed by the respective studies in the literature (Bagozzi \& Yi, 1990), CMIN/DF ratio below the threshold level of 3, CFI and IFI scores above 0.9 and RMSEA score below 0.10 are regarded as satisfactory levels. Additionally, standardized factor loadings for each scale are reported above 0.5 threshold level which requires no additional adjustment for the scale items. Intra-factor loadings of the scale items are presented in Table 1.

Table 1: Factor Loadings of Scale Items

\begin{tabular}{llcc}
\hline Scale & Items & Standardized Factor Loads & Unstandardized Factor Loads \\
\hline \multirow{3}{*}{ Green Trust } & TRU1 & 0.727 & 1.000 \\
& TRU2 & 0.534 & 0.850 \\
& TRU3 & 0.831 & 1.329 \\
\hline \multirow{3}{*}{ Green Satisfaction } & SAT1 & 0.817 & 1.000 \\
& SAT2 & 0.857 & 1.136 \\
& SAT3 & 0.882 & 1.234 \\
& SAT4 & 0.631 & 0.649 \\
\hline \multirow{3}{*}{ Green Image } & IMA1 & 0.843 & 1.000 \\
& IMA2 & 0.773 & 0.791 \\
& IMA3 & 0.921 & 1.067 \\
& IMA4 & 0.844 & 0.997 \\
& IMA5 & 0.883 & 1.037 \\
Green Brand Equity & IMA6 & 0.768 & 0.912 \\
\hline \multirow{2}{*}{ Performance Tolerance } & EQU1 & 0.808 & 1.000 \\
& EQU2 & 0.902 & 1.322 \\
& EQU3 & 0.805 & 0.808 \\
& EQU4 & 0.585 & 0.739 \\
\hline
\end{tabular}




\begin{tabular}{llll}
\hline & PERF3 & 1.006 & 1.579 \\
\hline \multirow{3}{*}{ Price Tolerance } & PRIC1 & 0.882 & 1.000 \\
& PRIC2 & 0.805 & 1.186 \\
& PRIC3 & 0.941 & 1.017 \\
\hline \multirow{3}{*}{ Communication Tolerance } & COM1 & 0.954 & 1.000 \\
& COM2 & 0.914 & 0.850 \\
& COM3 & 0.736 & 0.516 \\
\hline p<0.01 for all items & & \\
\hline
\end{tabular}

Following the confirmation of the construct validity, convergent validities of each scale were also checked through the calculation of the respective Average Variance Extracted (AVE) scores. AVE scores computed for each scale were above 0.50 level which is the minimum acceptable level reported in the respective studies (Byrne, 2010). In addition to the validity checks, a series of reliability checks were also conducted in order to confirm the reliability of each scale in the model. Both composite and internal reliability (Cronbach Alpha) scores calculated were above the minimum acceptable thresholds reported in the literature (Fornell \& Larcker, 1981). In the light of these results, the validity and reliability of the scales employed in the model were confirmed. The results of the convergent validity, discriminant validity, composite reliability and internal reliability checks are presented in Table 2.

Table 2: Validity and Reliability Checks

\begin{tabular}{|c|c|c|c|c|c|c|c|}
\hline Dimensions & 1 & 2 & 3 & 4 & 5 & 6 & 7 \\
\hline Green Trust & $(.708)$ & & & & & & \\
\hline Green Satisfaction & $0.339 * *$ & $(.803)$ & & & & & \\
\hline Green Image & 0.123 & -0.098 & $(.840)$ & & & & \\
\hline Green Brand Equity & $0.384 * *$ & $0.720 * *$ & 0.010 & $(.784)$ & & & \\
\hline Performance Tolerance & $0.178^{*}$ & $0.443 * *$ & $-0.223 * *$ & $0.412 * *$ & $(.963)$ & & \\
\hline Price Tolerance & $0.234 * *$ & $0.357 * *$ & -0.012 & $0.306^{* *}$ & $0.178^{*}$ & $(.877)$ & \\
\hline Communication Tolerance & 0.033 & $0.337 * *$ & -0.072 & $0.374 * *$ & $0.211 *$ & 0.071 & $(.873)$ \\
\hline Composite Reliability & .745 & .877 & .935 & .862 & .975 & .909 & .905 \\
\hline Average Variance Extracted (AVE) & .501 & .645 & .706 & .614 & .928 & .770 & .762 \\
\hline Cronbach $\alpha$ & .711 & .891 & .920 & .873 & .964 & .884 & .896 \\
\hline
\end{tabular}

\section{FINDINGS AND DISCUSSIONS}

\subsection{Findings}

Following the validation of the measurement model as well as the scales based on the CFA results, the structural model and the associated hypotheses are tested through the SEM analysis with maximum likelihood estimation methods. The overall fit indices computed resulted in satisfactory scores and indicated a good fit of the model $(X 2 / D F=1.071, C F I=0.930, I F I=0.937, R M S E A=$ 0.022). All of the paths estimated yielded statistically significant results except one, and the respective hypothesis were accepted. The results of the analysis confirmed that Green Brand Performance and Green Brand Trust have statistically significant and positive effects on Green Brand Equity (GBE). In turn, GBE, is found to be effective on the three dimensions of Customer Based Brand Tolerance (CBBT), namely Product Performance, Price Performance and Communication Performance. The results indicated that GBE has a positive influence in all dimensions of CBBT. The results of the hypothesis testing and the final structural model including the standardized coefficients for each path are presented in Table 3 and Figure 2, respectively. 
Table 3: Results of the Hypothesis Testing

\begin{tabular}{|clccc|}
\hline$\#$ & \multicolumn{1}{c}{ Relationships } & $\begin{array}{c}\text { Standardized } \\
\text { Coefficients }\end{array}$ & $\begin{array}{c}\text { Unstandardized } \\
\text { Coefficients }\end{array}$ & Result \\
\hline H1 & Green Brand Image $\rightarrow$ Green Brand Equity & 0.049 & 0.035 & Not Supported \\
H2 & Green Brand Satisfaction $\rightarrow$ Green Brand Equity & $0.729^{* *}$ & $0.707^{* *}$ & Accepted \\
H3 & Green Brand Trust $\rightarrow$ Green Brand Equity & $0.246^{*}$ & $0.266^{*}$ & Accepted \\
H4 & Green Brand Equity $\rightarrow$ Performance Toleration & $0.392^{* *}$ & $0.396^{* *}$ & Accepted \\
H5 & Green Brand Equity $\rightarrow$ Price Toleration & $0.318^{* *}$ & $0.272^{*}$ & Accepted \\
H6 & Green Brand Equity $\rightarrow$ Communication Toleration & $0.278^{*}$ & $0.473^{*}$ & Accepted \\
${ }^{* *}$ Significant at the 0.01 level; $*$ Significant at the 0.05 level & & & \\
\hline
\end{tabular}

Figure 2: Test Results of the Structural Model



\subsection{Academic and Managerial Implications}

This study integrates two inter-related constructs, namely Green Brand Equity (GBE) and Customer Based Brand Tolerance (CBBT) and sheds light into an unexplored investigation area in the marketing literature. In the light of the findings, there are some academic as well as managerial implications which need to be discussed. First of all, in line with the existing studies in the literature (Ha, 2020; Ng et al. 2014; Kang and Hur, 2012), green brand satisfaction and green brand trust are found to be affective on the GBE of companies in the personal care and cosmetics industry. The significant, positive and strong influence of green satisfaction on GBE was expected since there are many studies in the literature confirming the effect of satisfaction on This result was expected due to the previous findings in the literature which report also the positive influence of customer satisfaction on CBBE (Bekk et al., 2016; Kim et al. 2008). Similarly, another expected result was the significant and positive influence of brand trust on GBE since many studies in the marketing literature reported significant and positive effect of customer trust on the CBBE (Kim et al. 2008; Jevons and Gabbott, 2000). On the other hand, green brand image was not found to be affective on Green Brand Equity, which makes the findings of the previous studies conducted by Ha (2020), Ng et al. (2014) and Kang and Hur (2012) inconclusive. Another important academic implication of the findings is the significant and positive influence of GBE on the CBBT. Green Brand Equity is found to have a significant and positive effect on all three dimensions of CBBT, namely product performance price performance and communication performance. This significant influence was also expected taking into consideration the results of the previous 
studies which confirm the positive effect of CBBE on the positive response of consumers towards the marketing mix elements of the brands (Sözer, 2019; Kabadayı and Aygün, 2007; Kent and Allen, 1994). In addition to the academic implications of the results, there are also some managerial implications which needs to be considered. First of all, the results indicate that when consumers are satisfied with the green marketing practices of the brands and they trust to the brands in terms of their sincerity in involving into such practices, their GBE is positively influenced and becomes stronger. In order to generate such effect, brands need first to articulate the details of their green policies through marketing communications and public relations activities, and then they need further demonstrate how they adopt the policy into their marketing programs as well as business models. In addition to this, when the GBE is empowered with increasing green satisfaction and green trust, consumers become more tolerant towards the product/service failures of the brands at some extent. Moreover, they also be willing to pay more for the products of such brands and they become more tolerant towards the price increases. Finally, the receptivity of consumers towards the marketing communications of such brands becomes also much stronger when the brand has a strong GBE. It is an expected outcome especially when green practices of brands are aligned with the sensitivity of consumers related to the environmental issues. Thus, managers are recommended to periodically measure the strength of their GBE in order to maximize the benefits in terms of CBBT. A strong CBBT empowered by GBE will help brands to increase their customer equity and generate sustainable competitive advantage.

\section{CONCLUSION}

This study contributes to the existing literature by integrating Green Brand Equity (GBE) and Customer Based Brand Tolerance (CBBT) constructs in the retailing context. There are some remarks to be made regarding the contributions, limitations and suggestions for further research. First of all, despite the fact that there are vast number of studies, which investigated the determinants of the Green Brand Equity (GBE) and confirmed the impact of several determinants including green brand satisfaction, green brand trust and green brand image, this study leads the way for further investigation since the green brand image was not found to be significantly effective on the GBE. Another important contribution and novelty provided by this study is the finding related to the significant impact of GBE on the product, performance and communication tolerance dimensions.

In addition to the contributions provided by the study, there are also some limitations of the study in terms of generalizability which need to be mentioned. First of all, the participants of the study were female subjects living in Istanbul city. The choice of sample as female consumers limits the generalizability of the results covering gender types. Moreover, the geographic area of the study was limited to one city, Istanbul, which is also an issue in terms of generalizability of the results. Finally, the product category in the study was selected as personal care and cosmetics. In the light of the above mentioned limitations in terms of the generalizability of the results, there is a need for research studies with broader scope and coverage. Thus, further studies are recommended to be conducted also with the participation of male consumers, in a more expanded geographic area and finally, on other product categories.

\section{REFERENCES}

Aaker, D. A. (1991). Managing Brand Equity. New York: Free Press.

Agustin, C. \& Singh, J. (2005). Curvilinear Effects of Consumer Loyalty Determinants in Relational Exchanges. Journal of Marketing Research, 42(1): 96-108.

Aytekin, P. (2007). Yeşil Pazarlama Stratejileri. Sosyal Bilimler, 5(2): 1-20.

Bagozzi, R. P., \& Yi, Y. (1990). Assessing Method Variance in Multitrait-Multimethod Matrices: The Case of Self-Reported Affect and Perceptions at Work. Journal of Applied Psychology, 75(1):547-560.

Baumgartner, R. J., \& Rauter, R. (2017). Strategic perspectives of corporate sustainability management to develop a sustainable organization. J. Clean. Prod. 140: 81-92.

Bekk, M., Spörrle, M., Hedjasie, R., \& Kerschreiter, R. (2016). Greening the competitive advantage: antecedents and consequences of green brand equity. Quality \& Quantity, 50(4): 1727-1746.

Biel, A. L. (1992). How Brand Image Drives Brand Equity. Journal of Advertising Research, 12(November): RC6-RC12.

Butt, M. M., Mushtaq, S., Afzal, A., Khong, K. W., Ong, F. S., \& Ng, P. F. (2016). Integrating behavioral and branding perspectives to maximize green brand equity: a holistic approach. Business Strategy and the Environment, 26(4): 507-520.

Cantele, S. \& Cassia, F. (2020). Sustainability implementation in restaurants: A comprehensive model of drivers, barriers, and competitivenessmediated effects on firm performance. International Journal of Hospitality Management, 87(2020): 1-10. 
Chang, N. J., \& Fong, C. M. (2010). Green product quality, green corporate image, green customer satisfaction, and green customer loyalty. African Journal of Business Management, 4(13): 2836-2844.

Chen, Y. (2010). The Drivers of Green Brand Equity: Green Brand Image, Green Satisfaction, and Green Trust. Journal of Business Ethics, 93(2): 307319.

Cretu, A. E., \& Brodie, R. J. (2007). The influence of brand image and company reputation where manufacturers market to small firms: A customer value perspective. Industrial Marketing Management, 36(2): 230-240.

Davis, D. F., Golicic, S. L. \& Marquardt, A. J. (2008). Branding a B2B service: Does a brand differentiate a logistics service provider? Industrial Marketing Management, 37(2008): 218-227.

Doney, P. M. \& Cannon, J. P. (1997). An Examination of the Nature of Trust in Buyer-Seller Relationships. Journal of Marketing, 61 (April): 35-51.

Doorn, M. (2012). Tolerance. Sociopedia.isa. 1-15.

Elliot, R. \& Yannopoulou, N. (2007). The nature of trust in brands: a psychosocial model. European Journal of Marketing, 41(9/10): 988-998.

Faircloth, J. B., Capella, L. M., \& Alford, B. L. (2001). The Effect of Brand Attitude and Brand Image on Brand equity. Journal of Marketing Theory and Practice, 9(3), 61-75.

Fornell, C. \& Larcker, D. (1981). Evaluating Structural Equation Models with Unobservable Variables and Measurement Error. Journal of Marketing Research, 18(1): 39-50.

Gefen, D. \& Straub, D. W. (2004). Consumer Trust in B2C e-Commerce and the Importance of Social Presence: Experiments in e-Products and eServices. Omega 32(6): 407-424.

Gulati, R. (1995). Does familiarity breed trust? The Implications of repeated ties for contractual choice in alliances. The Academy of Management Journal, 38(1): 85-112.

Ha, M. T. (2020). Investigating green brand equity and its driving forces. Management Science Letters, 10(2020): 2385-2394.

Jalilvand, M. R., Samiei, N., \& Mahdavinia, S. H. (2011). The Effect of Brand Equity Components on Purchase Intention: An Application of Aaker's Model in the Automobile Industry. International Business and Management, 2(2): 149-158.

Jevons, C. and Gabbott, M. (2000). Trust, Brand Equity and Brand Reality in Internet Business Relationships: An Interdisciplinary Approach. Journal of Marketing Management, 16(6): 619-634.

Kabadayı, E. T. \& Aygün, İ. (2007). Determinants of Brand Loyalty and The Link Between Brand Loyalty and Price Tolerance. Boğaziçi Journal, 21(12): 21-35.

Kang, S. H. \& Hur, W. M. (2012). Investigating the antecedents of green brand equity: a sustainable development perspective. Corporate Social Responsibility and Environmental Management, 19(5): 306-316.

Keller K. L. (1993) Conceptualizing, measuring, and managing customer-based brand equity. Journal of Marketing, 57(1): 1-22.

Kent, R. J. \& Allen, C. T. (1994). Competitive Interference Effects in Consumer Memory for Advertising: The Role of Brand Familiarity. Journal of Marketing, 56(July): 97-105.

Kim, K. H., Kim, K., Kim, D., Kim, J., \& Kang, S. (2008). Brand equity in hospital marketing. Journal of Business Research, 6(1): 75-82.

Kim, H. \& Kim, W. G. (2005). The relationship between brand equity and firms 'performance in luxury hotels and chain restaurants. Tourism Management, 26(2005): 549-560.

Kotler, P. \& Keller, K. L. (2016). Marketing Management. 15th Edition. Tamil Nadu: Pearson.

Kumar, P. (2015). State of green marketing research over 25 years (1990-2014): Literature survey and classification. Marketing Intelligence \& Planning, 34(1): 137-158.

Leone, R. P., Rao, V. R., Keller, K. L., Luo, A. M., McAlister, L. \& Srivastava, R. (2006). Linking Brand Equity to Customer Equity. Journal of Service Research, 9(2): 125-138.

Levy, S. J. (1985). Dreams, fairy tales, animals, and cars. Psychology and Marketing, 2(2): 67-81.

Namkung, Y., \& Jang, S. C. (2013). Effects of restaurant green practices on brand equity formation: Do green practices really matter? International Journal of Hospitality Management, 33: 85-95.

Ng, P., Butt, M., Khong, K., \& Ong, F. S. (2014). Antecedents of Green Brand Equity: An Integrated Approach. Journal of Business Ethics, 121(2): 203-215. 
Oliver, R. L. (1993). Cognitive, affective, and attribute bases of the satisfaction response. Journal of Consumer Research, 20(3): 418-430.

Ostrom, A., \& lacobucci, D. (1995). Consumer trade-offs and the evaluation of services. Journal of Marketing, 59(1): 17-28.

Ottman, J. A. (1992). Green Marketing, NTC Business Books, Chicago: USA.

Polonsky, M. (1994). An Introduction to Green Marketing. Electronic Green Journal, 1(2).

Singh, J. \& Sirdeshmukh, D. (2000). Agency and Trust Mechanisms in Consumer Satisfaction and Loyalty Judgements. Journal of the Academy of Marketing Science, 28(1): 150-167.

Solomon, M. R. (2018). Consumer Behavior: Buying, Having and Being. 12th Edition. UK: Pearson.

Sözer, E. G. (2019). Customer Based Brand Tolerance (CBBT): Scale Development and Validation. Business \& Management Studies: An International Journal, $7(5), 2610-2635$.

Taylor, S.A., Celuch, K. \& Goodwin, S. (2004). The importance of brand equity to customer loyalty. Journal of product and Brand Management, 13(4-5): 217-227. 